\title{
Research Contributions in Current Science Journal: A Bibliometric Study
}

\author{
${ }^{1}$ Sanjeevi, K., ${ }^{2}$ Sivakumaran, K., ${ }^{3}$ Natarajan, V. \\ ${ }^{1}$ Assistant Professor \\ Dept. of Library \& Information Science \\ Annamalai University, Annamalainagar - 608 002, India \\ sanno@gmail.com \\ ${ }^{2,3}$ Research Scholars \\ Dept. of Library \& Information Science \\ Annamalai University, Annamalainagar-608 002, India
}

ABSTRACT: This paper analyzed the research contributions among year-wise publication, authorship pattern among the published article, subject, country and state-wise distribution published in Current Science Journal from 2015 to 2017. The growth of literature during the study period is gradually increasing and maximum number of articles (83) published in 2017. The multiple authored contributions are occupied first position compared to double and single authors. Among top ten countries, contributions from India is higher 481 articles compared to others. The subject-wise distribution Agricultural Science contribution is higher (42 articles) compared to divisions of Science discipline.

Keywords: Bibliometrics, Authorship Pattern, Current Science, Subject Distribution

Received: 1 September 2018, Revised 9 October 2018, Accepted 10 October 2018

DOI: $10.6025 / \mathrm{jitr} / 2019 / 10 / 1 / 7-11$

(C) 2019 DLINE. All Rights Reserved

\section{Introduction}

Ranganathan (1948) has suggested the terms 'Librametry' at the ASLIB Conference in Leamington Spa on the lines of biometry and econometry etc. The Librametry is primarily aims at the quantitative analysis of the management of libraries and bibliometrics is limited to recorded knowledge. Bibliometrics is unique type of research method. It has commanded the attention of numerous individuals in library and information science. The measurement of biblographic information offers the promise of providing and it will resolve many practical problems.

Alan Pritchard (1969), who first used the word "Bibliometrics" described as "the application of mathematical and statistical methods to books and other media of communication". This was paraphrased by Robert A. Fairthone (1969) as "Quantitative treatment of the properties of recorded discourse and behaviour appertaining to it." Diodato (1994) has defined and stated that 
the study of publications and communication patterns in the distribution of information by using mathematical and statistical techniques, from counting to calculus. The present study has analyzed the year-wise, subject-wise, Institution-wise distribution and Authorship pattern on the research articles published on Current Science during the period from 2015 to 2017.

\section{Review of Literature}

Review of related study avoids the duplication work that has already been done in that area. It also helps the researcher to study the different aspects of the problem. It enables the researcher to identify the unexplored areas, in order to create new grounds for research. More number of researches has been carried out in the specified topic. Few related reviews are mentioned below:

Chiemeke et al., (2009) have investigated research outputs of Nigerian Tertiary Institution using nine journals randomly selected from African Journals Online (AJOL). They found out that the volume of research papers from Nigeria in the Journals analysed amounted to $39.1 \%$ of the total number of publications in those journals in (1999-2005). The problem with this study is they did not focus in a subject area, any particular institution and few journals. The bibliometric study on Malayasian Journal of Computer Science were evaluated the article productivity of the journal from 1985 to 2007 using Lotka's Law Zainab et al. (2009). Akhtar Hussain et al. (2011) have analyzed a bibliometric study of 578 articles were published during the period from 2000 to 2010 in the Electronic Library journal. Further the authors the year-wise distribution of articles, category-wise classification of papers, subject-wise distribution of articles, authorship patterns, and institutions-wise distribution of contributions. Manivannan (2013) has studied the authorship pattern, country-wise, subject-wise research productivity in Indian Journal of Medical Research from 1997 to 2011.

\section{Objectives}

- To study the year-wise publication.

- To find out authorship pattern among the published article.

- To analyze the subject-wise distribution.

- To study the country-wise distribution.

- To examine the State-wise research contributions

\section{Methodology}

The primary data for the present research was collected the information from the Current Science Journal printed version available in the Centre of Advanced Study in Marine Biology during the period from 2015 to 2017. The secondary data for research has been collected from the journal articles, books, online sources, etc. The collected data were tabulated in the Excel sheet for analysis. The simple percentage method is adopted.

\section{About Current Science [www.currentscience.ac.in]}

Current Science Journal was published every fortnight in collaboration with the Indian Academy of Sciences. It is the leading interdisciplinary science journal published in India. It was started in 1932 by the then stalwarts of Indian science such as CV Raman, Birbal Sahni, Meghnad Saha, Martin Foster and S.S. Bhatnagar. In 2011, the journal completed one hundred volumes. The journal is intended as a medium for communication and discussion of important issues that concern science and scientific activities. Current Science is indexed by Web of Science, Current Contents, Geobase, Chemical Abstracts, IndMed and Scopus. The Impact Factor of the journal for the year 2016 is 0.843.

Subramanyam (1983) formula is adopted to examine the extent of collaborations in research has been measured with the help of authorship pattern of published papers.

$$
C=\frac{N_{m}}{N_{m}+N_{s}}
$$

\begin{tabular}{lllllll}
\hline 8 & Journal of Information Technology Review Volume 10 & Number 1 & February 2019 \\
\hline
\end{tabular} 
where,

$C=$ extent of collaboration in a discipline

$N_{m}=$ number of multiple authored papers in the discipline published during the year and

$N_{s}=$ number of single authored papers.

\section{Results}

\begin{tabular}{|c|c|c|c|c|c|}
\hline Years & Volume & Issues & Research Articles & Year Wise Total & Cumulative Total \\
\hline 2015 & 108 & 12 & 37 & \multirow{2}{*}{78} & 37 \\
\hline 2015 & 109 & 12 & 41 & & 78 \\
\hline 2016 & 110 & 12 & 59 & \multirow{2}{*}{155} & 137 \\
\hline 2016 & 111 & 12 & 56 & & 193 \\
\hline 2017 & 112 & 12 & 83 & \multirow{2}{*}{155} & 276 \\
\hline \multirow[t]{2}{*}{2017} & 113 & 12 & 72 & & 348 \\
\hline & & 72 & 348 & 348 & 348 \\
\hline
\end{tabular}

Table 1. Year-wise distribution

The year-wise distribution of articles published in the Current Science Journal during the study period was given in Table-1. It is clearly shown that totally 72 issues were published in five years from 2015 to 2017 . The maximum numbers of 83 research articles were published in 2017 and least number ( 37 articles) were published in 2015 . The publication trend in published articles is gradually increasing.

\begin{tabular}{|l|l|c|c|c|c|}
\hline Year & Single Author & D ouble Author & Multiple Author & Cumulative Total & Percentage \\
\hline 2015 & $1(1.28 \%)$ & $15(19.23 \%)$ & $62(79.48 \%)$ & $78(22.41 \%)$ & 2015 \\
\hline 2016 & $4(3.47 \%)$ & $28(24.34 \%)$ & $83(72.17 \%)$ & $115(33.04 \%)$ & 2016 \\
\hline 2017 & $4(2.58 \%)$ & $32(20.64 \%)$ & $119(76.77 \%)$ & $155(44.54 \%)$ & 2017 \\
\hline Total & $\mathbf{9}(\mathbf{2 . 5 8 \% )}$ & $\mathbf{7 5}(\mathbf{2 1 . 5 5 \% )}$ & $\mathbf{2 6 4}(\mathbf{7 5 . 8 6 \% )}$ & $\mathbf{3 4 8}(\mathbf{1 0 0 \% )}$ & Total \\
\hline
\end{tabular}

Table 2. Authorship pattern

The above table clearly shown that Multiple authors have contributed more (75.86\%) followed by double author and single author contributions $21.55 \%$ and $2.58 \%$ respectively.

The subject-wise distribution of published articles during the study period is given below:

During the study period, contributions from Agricultural Science is occupied first position (42 articles) followed by Climate change (32 articles). The contributions other branches in science discipline viz., Chemistry, Botany, Biochemistry Biotechnology etc. contributed below 30 articles.

Among top 10 countries, India has contributed more (481 articles) and occupied first position followed by China (42 articles). The contribution level of rest of the eight countries is below 10 articles. 


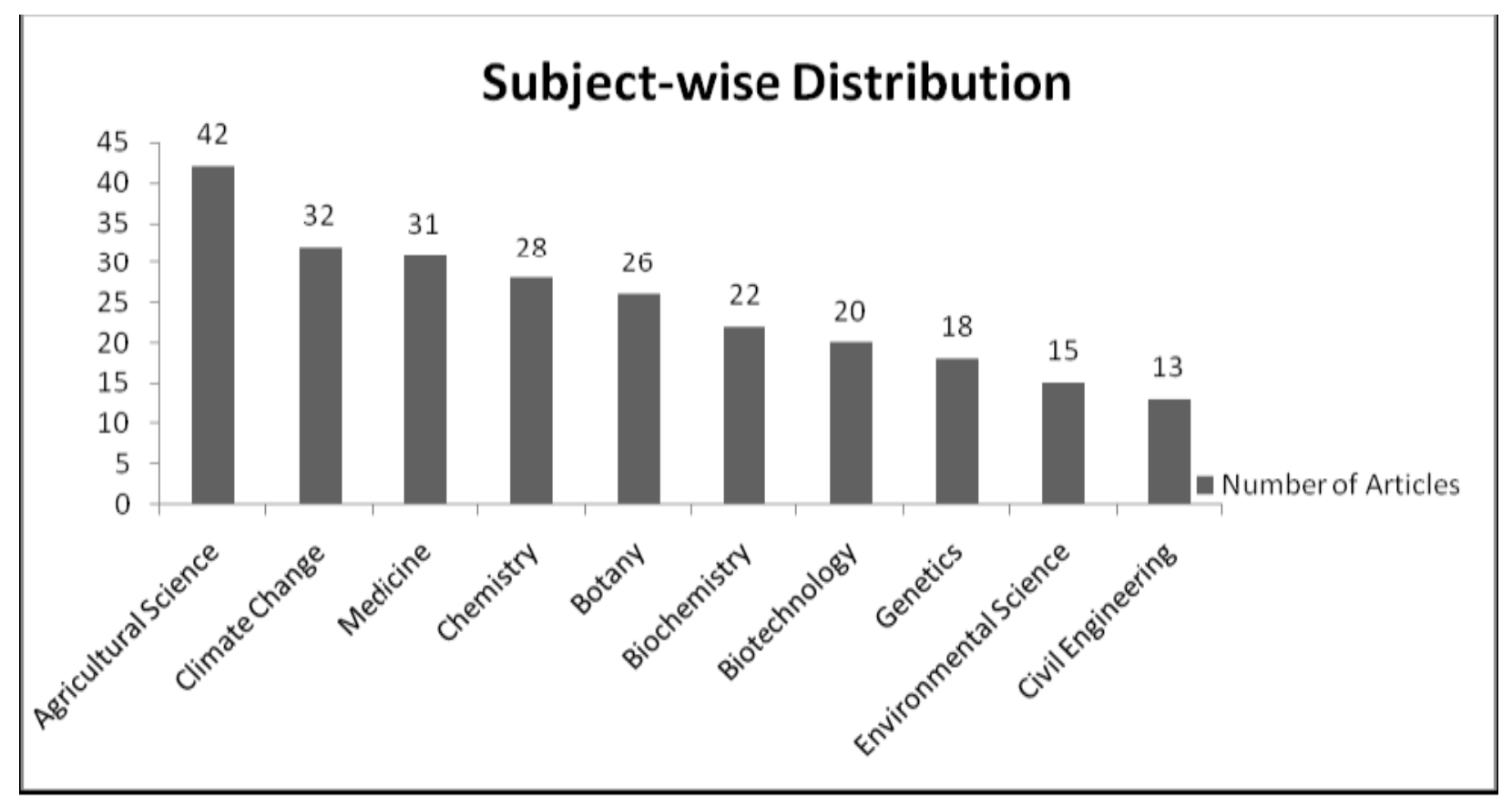

\begin{tabular}{|l|l|l|}
\hline Sl. No. & Country & No. of Articles \\
\hline 1 & India & 481 \\
\hline 2 & China & 42 \\
\hline 3 & Iran & 9 \\
\hline 4 & Malaysia & 9 \\
\hline 5 & UK & 9 \\
\hline 6 & Serbia & 6 \\
\hline 7 & Nigeria & 5 \\
\hline 8 & Saudi Arabia & 5 \\
\hline 9 & UK & 4 \\
\hline 10 & Australia & 3 \\
\hline
\end{tabular}

Table 3. Country-wise Distribution

The contributions among top 10 States, Maharashtra has contributed 57 articles, New Delhi (52 articles) and Tamil Nadu (48 articles). The rest of states have contributed below 45 articles.

\section{Findings}

The above revealed that year-wise contribution on current science journal is gradually increasing. The multiple authors have contributed more articles. The experts other branches in science discipline like Chemistry, Biochemistry, Environmental Sciences, Biotechnology are to be encouraged and to contribute their valuable research findings in Current Science which was indexed by Web of Science, Current Contents, Geobase, Chemical Abstracts, IndMed and Scopus databases. The researchers and academic communities databases are widely accessed these databases to update their knowledge.

\begin{tabular}{llllll}
\hline 10 & Journal of Information Technology Review Volume 10 & Number & 1 & February 2019 \\
\hline
\end{tabular}




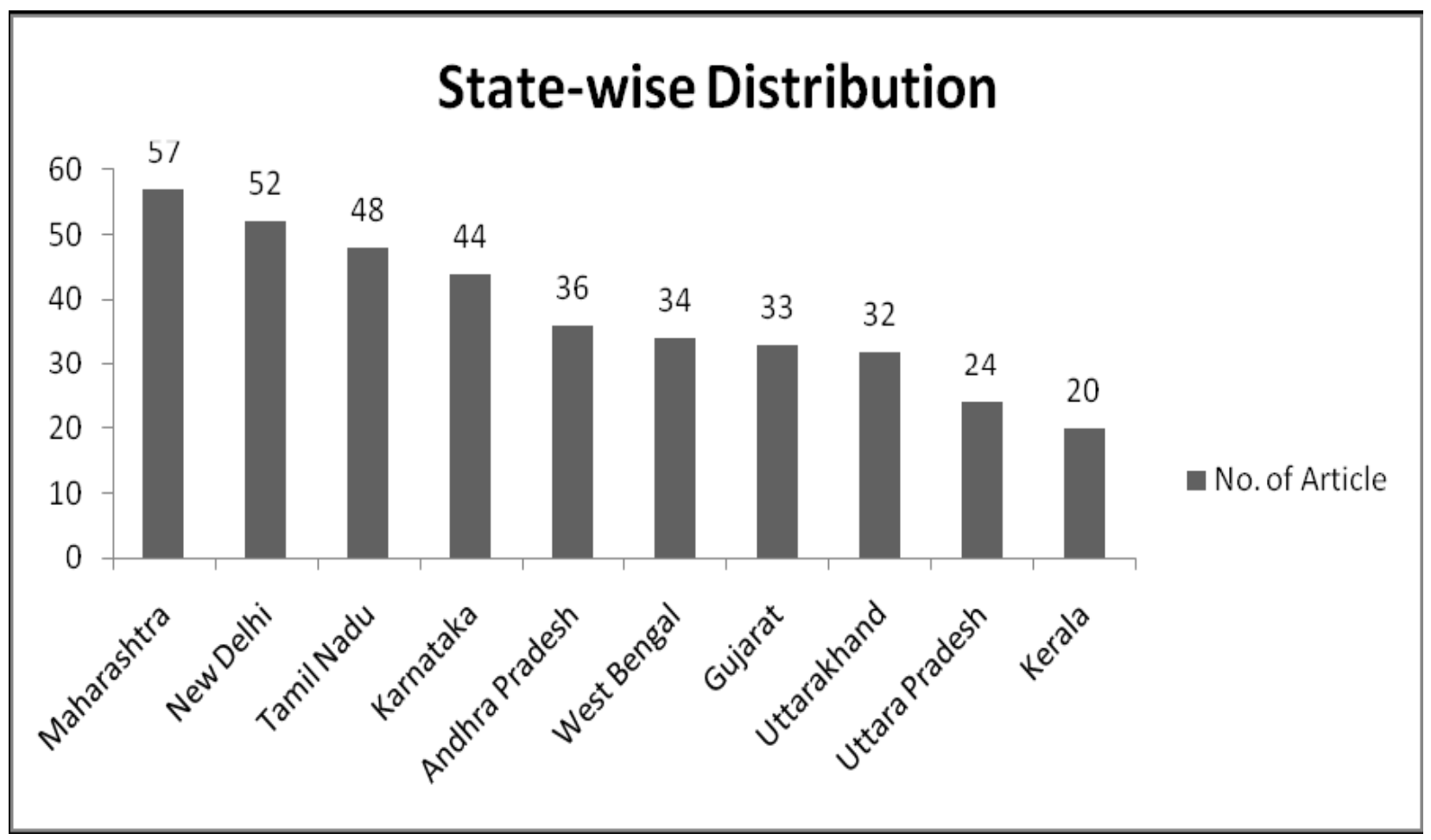

\section{References}

[1] Chiemeke, S., Longe, O. B., Longe, F. A., Shaib, I. O. (2009). Research outputs from Nigerian tertiary institutions: an empirical appraisal. Library Philosophy and Practice. Available: http://libr.unl.edu/LPP/chiemeke-longe-longe-shaib.htm

[2] Zainab, A. N., Ani, K. W. U., Anur, N. B. (2009). A single journal study: Malaysian Journal of Computer Science. Malaysian Journal of Computer Science, 22 (1) 1-18.

[3] Hussain, Akhtar., Fatima, Nishat., Devendra Kumar (2011). Bibliometric analysis of the ‘Electronic Library’ Journal (20002010). Webology, 8(1).

[4] Manivannan, G. (2013). The Indian Journal of Medical Research : A Bibliometric analysis. Ph.D. Thesis, Annamala Univrsity, p. 219.

[5] Fairthrone, R. A. (1969). Empirical hyperbolic distribution (Bradford Zipf-Mandelbrot) for bibliometric description and prediction. J. Doc. 25, p. 319-343.

[6] Diodato, V. (1994). Statistical bibliography; An interim Bibliography. North - Western Polytechnic school of Librarianship, London.

[7] Pritchard, A. (1969). Statistical Bibliography or bibliometrics?. Journal of Documentation, 25 (4) 348-349.

[8] Subramanyam, K. (1983). Bibliometric studies of research collaboration : A review. Journal of Information Science, 6. 3-5. 